OPEN ACCESS

Edited by:

Christine Happle, Hannover Medical School,

Germany

Reviewed by:

Magali Irla,

Institut national de la santé

et de la recherche

médicale, France

Dennis O. Adeegbe,

Harvard Medical School,

United States

*Correspondence:

David W. Scott

david.scott@usuhs.edu

Specialty section:

This article was submitted to

Immunological Tolerance and Regulation,

a section of the journal

Frontiers in Immunology

Received: 22 June 2017

Accepted: 25 August 2017

Published: 21 September 2017

Citation:

Adair PR, Kim YC, Zhang A-H, Yoon J and Scott DW (2017) Human Tregs Made Antigen Specific by Gene

Modification: The Power to Treat

Autoimmunity and Antidrug

Antibodies with Precision.

Front. Immunol. 8:1117.

doi: 10.3389/fimmu.2017.01117

\section{Human Tregs Made Antigen Specific by Gene Modification: The Power to Treat Autoimmunity and Antidrug Antibodies with Precision}

\author{
Patrick R. Adair, Yong Chan Kim, Ai-Hong Zhang, Jeongheon Yoon and David W. Scott \\ Department of Medicine, Uniformed Services University of the Health Sciences, Bethesda, MD, United States
}

Human regulatory CD4+ $\mathrm{T}$ cells (Tregs) are potent immunosuppressive lymphocytes responsible for immune tolerance and homeostasis. Since the seminal reports identifying Tregs, vast research has been channeled into understanding their genesis, signature molecular markers, mechanisms of suppression, and role in disease. This research has opened the doors for Tregs as a potential therapeutic for diseases and disorders such as multiple sclerosis, type I diabetes, transplantation, and immune responses to protein therapeutics, like factor VIII. Seminal clinical trials have used polyclonal Tregs, but the frequency of antigen-specific Tregs among polyclonal populations is low, and polyclonal Tregs may risk non-specific immunosuppression. Antigen-specific Treg therapy, which uses genetically modified Tregs expressing receptors specific for target antigens, greatly mitigates this risk. Building on the principles of T-cell receptor cloning, chimeric antigen receptors (CARs), and a novel CAR derivative, called B-cell antibody receptors, our lab has developed different types of antigen-specific Tregs. This review discusses the current research and optimization of gene-modified antigen-specific human Tregs in our lab in several disease models. The preparations and considerations for clinical use of such Tregs also are discussed.

\section{Keywords: human regulatory CD4 ${ }^{+} \mathrm{T}$ cells, Tregs, hemophilia A, antigen-specific Tregs, experimental autoimmune} encephalomyelitis, chimeric antigen receptor, $B$ cell antibody receptors

\section{INTRODUCTION}

Human regulatory $\mathrm{CD} 4^{+} \mathrm{T}$ cells (Tregs) are a subset of adaptive lymphocytes well characterized for their immunosuppressive functions and maintenance of immunological tolerance. Tregs are broadly grouped into two categories, either natural (i.e., thymus derived) or induced (i.e., peripherally derived). Natural Tregs (nTregs) represent between 2 and $8 \%$ of $\mathrm{CD} 4^{+} \mathrm{T}$ cells in healthy donor peripheral blood, whereas induced Tregs can be generated by expansion of $\mathrm{CD} 4^{+} \mathrm{T}$ cells in the presence of TGF $\beta$. The importance of Tregs in immune regulation and brokering tolerance has been robustly demonstrated (1-9), and expanded polyclonal Tregs are being developed for clinical applications. In this review, however, we summarize studies in our lab designed to generate antigenspecific nTregs by transduction of specific receptors.

Engineering antigen-specific $\mathrm{T}$ cells by gene modification has proven to be an invaluable immunological technology (10). In addition to exogenous T-cell receptors (TCRs), chimeric antigen 
receptors (CARs) containing single chain variable fragments $(\mathrm{scFv})$ are also used to redirect polyclonal $\mathrm{T}$ cells to a defined specificity. We have also engineered Tregs to express antigens or antigen fragments that can be recognized by B-cell receptors, which we refer to as B-cell antibody receptors (BARs). For BARs, the $s c F v$ of the CAR is replaced with an antigen or its domain. The exogenous TCRs are generally cloned from $\mathrm{T}$ cells present in diseased tissue, such as tumor-infiltrating lymphocytes, pancreatic islets, or multiple sclerosis (MS) lesions and are human leukocyte antigen (HLA) (11-15). The CARs, which are synthetic molecules, are typically comprised of $\mathrm{scFv}$ fused to $\mathrm{T}$ cell co-stimulatory proteins and $\mathrm{CD} 3 \zeta$ chain. The $\mathrm{scFv}$ portion of the CAR can be derived from phage display technology or traditional monoclonal antibody production (15-19). The antibody-derived properties of the CAR free it from HLA restriction. TCRs or CARs have traditionally been used to engineer effector $\mathrm{T}$ cells, predominantly $\mathrm{CD}^{+}$cytotoxic cells. The multiple design iterations, clinical successes (e.g., against melanoma and acute lymphoblastic leukemia) of TCR- and CAR gene-modified cells have been extensively reviewed by our group (20) and others (21-25). As noted above, our group and Ellebrecht et al. independently designed a novel method of engineering antigen-specific $\mathrm{T}$ cells with antigen domains, called
BAR in our lab and called chimeric autoantibody receptor by the Payne group (26). This antigen domain targets pathogenic antibody secreting cells or their precursors with specific surface B-cell immunoglobulin (Ig) receptors (BCR). We have adapted these redirecting technologies to human Tregs with the goal of improving future Treg therapy in clinical trials.

Here, we chronologically review the development of antigenspecific human Tregs by gene modification in our lab. Specifically we describe the use of TCR (Figure 1A), CAR (Figure 1B), and BAR (Figure 1C) Treg therapy in the context of disease models for hemophilia A and MS. The important conclusions from our experiments as well as future directions and considerations for gene-modified Tregs as a therapeutic are discussed.

\section{nTregs THERAPY: POLYCLONAL OR SPECIFIC}

Phenotypically, peripheral blood nTregs are identified by high surface expression of CD25 (IL-2 receptor $\alpha$ chain), low expression of CD127 (IL-7 $\alpha$ receptor), low to negative expression of CD45RA, and expression of the transcription factors, Foxp 3 and Helios. Further markers such as the Treg-specific demethylated

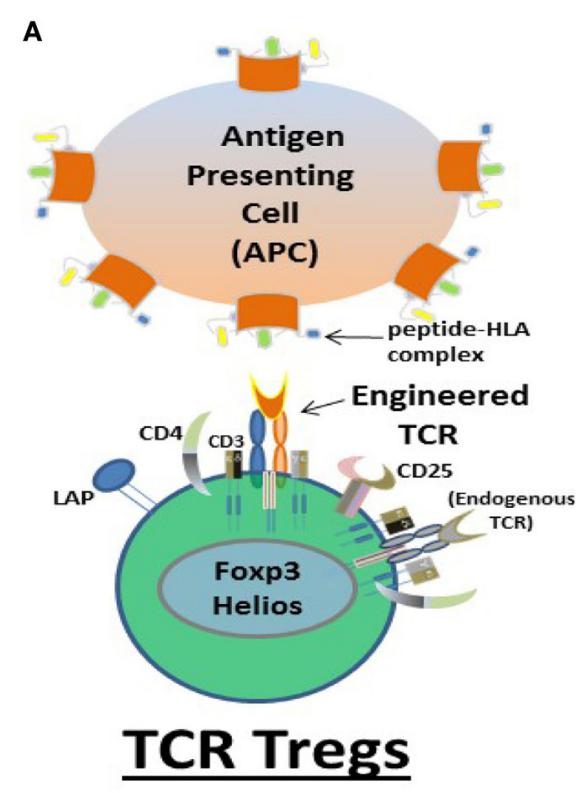

T cell receptor (TCR) engineered Tregs express an exogenous TCR with specificity for a target peptide epitope in the context of an MHC /HLA class II molecule and so are $\mathrm{MHC}$ restricted. This peptide-HLA complex is expressed on the surface of antigenpresenting cells in proximity of pathogenic T cells. The endogenous TCR can be edited out and suicide genes added.

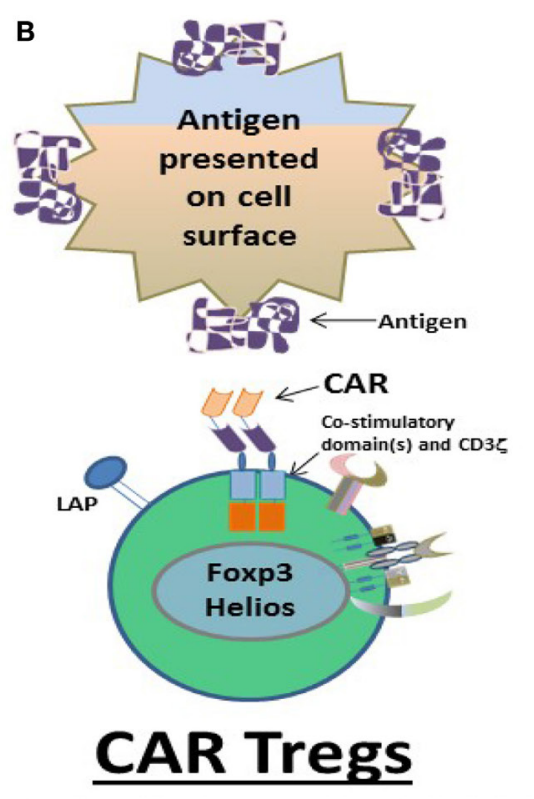

Chimeric Antigen Receptor (CAR) Tregs are comprised of an scFv antibody fragment expressed on the cell surface fused with intracellular T-cell co-stimulatory domains (e.g., CD28, 41BB) and an activation domain $\mathrm{CD} 3 \zeta$. CAR Tregs can recognize conformational epitopes of a target antigen expressed on a cell surface (B cells or APCs), but are not $\mathrm{MHC}$ restricted.

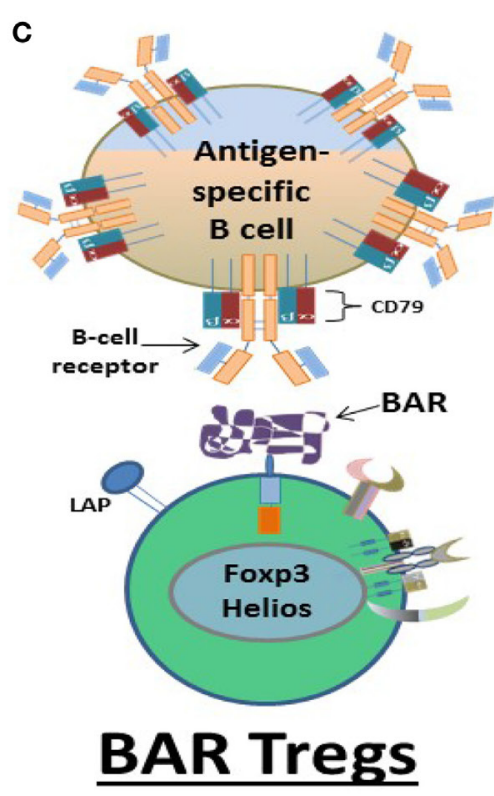

B-cell Antibody Receptor (BAR) Tregs are comprised of an antigen or its domains expressed on the cell surface, fused with intracellular T-cell co-stimulatory domains (e.g., CD28, 41BB) and an activation domain $\mathrm{CD} 3 \zeta$. BAR Tregs are recognized by the BCR on pathogenic antibody secreting B cells and are not $\mathrm{MHC}$ restricted.

FIGURE 1 | Types of gene-modified antigen-specific human regulatory CD4+ $\mathrm{T}$ cells (Tregs). Antigen-specific (A) T-cell receptor (TCR), (B) chimeric antigen receptor (CAR), and (C) B-cell antibody receptor (BAR) Tregs have been designed by the Scott lab as potential therapeutics to ameliorate autoimmune diseases and/or immune responses to biotherapeutics in monogenic diseases, for example. TCR, CAR, and BAR Tregs each have unique properties that can be exploited as treatments geared to the different pathophysiologies of such diseases and/or adverse immune responses. The structure and targeting moieties/cells of TCR, CAR, and BAR Tregs are briefly described and depicted. 
region, glycoprotein A repetitions predominant protein (GARP), glucocorticoid-induced TNFR family-related gene (GITR), latency-associated peptide (LAP), CTLA-4, CD27, CD73, and CD39 among others also aid in nTreg identification (27-36).

FoxP3 was identified from early studies with scurfy mice, which have an idiopathic mutation in the Foxp3 gene and develop systemic multi-organ autoimmunity $(37,38)$. In humans, the importance of Tregs is evident in the debilitating and often fatal polyendocrinopathy, enteropathy, X-linked (IPEX) syndrome which is linked to mutations in the Foxp3 gene $(39,40)$. The causal link between dysfunctional Tregs and autoimmunity set the stage for using functional Tregs to treat and possibly prevent it. Indeed adoptive Treg therapy to treat animal models of autoimmunity such as experimental autoimmune encephalomyelitis (EAE), arthritis, inflammatory bowel disease, and uveitis among others has proven successful and served as proof of concept for Treg therapy translational use (41-46).

Phase 1 clinical trials using human Tregs have involved participants suffering from acute graft versus host disease (GVHD) following stem cell transplants (47) or type I diabetes (T1D) (48). For the GVHD trial, all participants were infused with umbilical cord blood-derived polyclonal Tregs. No infusion related toxicities or adverse events were reported during the trial period. However, the authors concluded that a randomized control group receiving no Tregs was necessary to properly access treatment efficacy. The T1D trial used autologous peripheral blood-derived polyclonal Tregs. This was a dose escalation phase 1 trial. Treatment efficacy was not accessed, but the escalation protocols and safety profile of this trial has led to a phase 2 trial as of 2017 (49). Further trials using polyclonal Tregs to treat lupus and GVHD from kidney transplants and liver disease have also been initiated. ${ }^{1}$

The majority of these clinical trials have used polyclonal Tregs. While the success of polyclonal Tregs has been promising, the amount of cells needed for infusions is large (believed to be in the $10^{9}-10^{10}$ range) and the threat of global immune suppression is possible; indeed, one report cites viral reactivation after infusion of polyclonal Tregs (47) and tumor occurrence/recurrence is of concern given the correlation between Tregs and tumor survival $(50,51)$. Moreover, polyclonal human Tregs are not a homogenous population which may introduce unwanted variability and a lack of efficacy to their therapeutic potential (36, 52-54). To overcome these drawbacks, we and others believe that using antigen-specific Tregs of a defined homogenous population will require fewer cells to exert their regulatory effects and confer more localized and targeted suppression.

The occurrence of a particular antigen-specific $\mathrm{T}$ cell is very low, on the order of 1 in every $10^{5}-10^{7} \mathrm{~T}$ cells (55). This greatly hinders the ability to isolate and expand such rare cells. However, in certain disease states or conditions where a target antigen or group of antigens is/are known, the clonal expansion of an antigen-specific $\mathrm{T}$ cell facilitates its detection and isolation by molecular methods. Such methods include tetramer-guided epitope mapping and peptide MHC microarrays (56-59). Since

${ }^{1}$ Available from: https://clinicaltrials.gov/ct2/results?term=adoptive+treg+therapy\& Search $=$ Search the TCR traditionally endows a T cell with its specificity, extracting the TCR cDNA sequence from the expanded cells and cloning it into a viral expression vector allows researchers to engineer antigen-specific T cells.

\section{HUMAN Tregs GENE MODIFIED TO EXPRESS AN FVIII-SPECIFIC TCR}

One disease model used in our lab to study the therapeutic potential of antigen-specific Tregs is hemophilia A. Hemophilia A is an $\mathrm{X}$-linked bleeding disorder caused by mutations in the factor 8 (F8) gene, which encodes the blood coagulation protein, FVIII. Because of its monogenic etiology, the disorder can be treated with recombinant or plasma derived FVIII replacement therapy. Unfortunately, a large subset of those receiving replacement FVIII develop an antidrug antibody response. These antibodies (referred to as "inhibitors") can neutralize the FVIII, rendering this lifesaving treatment ineffective. Inhibitor formation requires $\mathrm{CD}^{+} \mathrm{T}$ cell help $(60,61)$, and is largely directed to the A2 and C2 domains of the FVIII protein.

The standard treatment for inhibitors is called immune tolerance induction (ITI). ITI consists of high dose infusions of FVIII for a period of one or more years. Although it has met with some clinical success, ITI does not work for all inhibitor cases. Thus, alternative approaches for inducing tolerance in these unsuccessful cases or preventing inhibitor responses, in the first place, are of clinical importance.

In collaboration with the lab of Dr. Kathleen Pratt, we successfully isolated, cloned and sequenced HLA-DRB1*01:01 (DR1)restricted TCRs specific for an epitope in the C2 domain of FVIII. The TCRs were isolated from $\mathrm{CD} 4^{+} \mathrm{T}$ cell clones of a hemophilia A subject at different time points after clonal expansion (62).

As reported in 2015 (63), we sorted human nTregs from healthy donor peripheral blood mononuclear cells (PBMCs) and transduced them with retroviral particles encoding one of these C2 domain specific TCRs, referred to as 17195. Transduced Tregs were then sorted and expanded in the presence of antihuman CD3, autologous $\gamma$-irradiated PBMCs, and oligodeoxynucleotides (ODN). Kim et al. have shown that these ODN maintain the Treg phenotype better than inclusion of rapamycin during the critical rapid expansion period (64).

An important point with ex vivo expansion of human gene-modified Tregs is to determine the activation status of the Tregs during and/or at the end of the expansion. Initial in vitro activation of sorted Tregs for 3-5 days is necessary for retro- or lentiviral gene transfer, followed by large-scale expansion for 10-12 days with IL-2, but without TCR or anti-CD3 stimulation. This expansion step generally can be repeated for up to two more cycles. In most cases, successfully expanded gene-modified Tregs do not retain their activation status due to the long-term expansion conditions without cognate/specific antigen (e.g., TCR) or anti-CD3 stimulation. Nonetheless, in vitro confirmation of gene-modified Treg activation with specific antigen is mandatory before testing these Tregs in vivo. Such confirmation provides a functional estimation of the Treg responsiveness. For this, surface expression of GARP, LAP, and 
CD25 as well as the induction of Foxp3 and Helios are analyzed by flow cytometry at $24-48 \mathrm{~h}$ post in vitro activation with cognate antigen and PBMCs $(63,65)$.

Tregs expressing the 17195 TCR proliferated in an antigenspecific manner and, importantly, maintained their Treg phenotype. Moreover, as mentioned above, these cells upregulated the Tregs markers Foxp3, Helios, GARP, LAP, and CD25 when stimulated with specific peptide. This phenotypic response was mirrored by the fact that they were able to prevent FVIII-specific effector cells from proliferating, as demonstrated in an in vitro suppression assay. Of clinical note, these Tregs also robustly diminished FVIII antibody production in splenocytes of FVIII-immunized HLA DR1 transgenic hemophilic mice in vitro and could prevent anti-FVIII formation in vivo in a xenogeneic transfer system.

\section{HUMAN Tregs GENE MODIFIED TO EXPRESS AN FVIII-SPECIFIC CAR}

Following the promising results and lessons gleaned from the FVIII-specific TCR gene-modified Tregs, we sought to design a FVIII-specific CAR Treg. CAR Tregs would allow us to test, without HLA restriction, the inhibition of both FVIII-specific antibody production and effector T cell proliferation. In collaboration with the lab of Drs. Anja Schmidt and Christoph Königs, Yoon et al. published results of human FVIII-specific CAR Tregs, referred to as ANS8 CAR Tregs (65). The human scFv region of the CAR was isolated by phage display and confirmed specific for the A2 domain of FVIII by competitive ELISA using known monoclonals against this domain (66). ANS8 CAR Tregs proliferated in response to FVIII and also concomitantly upregulated Foxp3 expression. These CAR Tregs suppressed the proliferation of FVIII-specific effector T cells. Moreover, these CAR Tregs also exhibited bystander suppression as they were able to prevent the proliferation of HLA DR2-restricted T effector cells specific for a myelin basic protein $(\mathrm{MBP})$ peptide in the presence of appropriate antigen-presenting cells. Strikingly, when tested in vivo, ANS8 CAR Tregs were able to prevent FVIII antibody titers prophylactically, similar to TCR-transduced (17195) Tregs. The prevention of the anti-FVIII response was sustained up to 8 weeks despite the rejections of the transferred human Tregs in immunocompetent mice. This emphasized the potency of the ANS8 CAR and TCR-transduced Tregs and has prompted us to design in vivo therapeutic protocols for FVIII antibody prevention.

\section{HUMAN Tregs GENE MODIFIED TO EXPRESS A BAR SPECIFIC FOR FVIII INHIBITORS}

To test whether engineered Tregs could directly suppress B cells, we designed a third engineered $\mathrm{T}$ cell model that would express antigen and would directly interact with specific B cells via their BCR. Thus, our latest gene-modified human Tregs are engineered to express either the immunodominant A2 or C2 domains of FVIII, fused to $\mathrm{T}$ cell co-stimulatory and signaling domains, so called "BAR" for B-cell antibody receptor. It has been shown in animal models of autoimmunity and suggested in IPEX patients that Tregs may be able to directly suppress pathogenic B cells (67-70). In light of these studies, we hypothesized that BAR engineered Tregs directly suppress FVIII-specific B cells via interaction with their BCR and may possibly suppress other FVIII-specific effector T cells co-localized in the local milieu.

Zhang et al. (71) in our lab showed that A2 and C2 BAR Tregs maintained Treg-specific markers, including Foxp3 and Helios, after long-term expansion in vitro. Importantly, we showed that these BAR Tregs also potently suppressed FVIII antibody formation in vitro and in vivo from FVIII-immunized hemophilic mice, thus providing a third model of specific Tregs. The mechanism of this suppression is discussed below.

\section{HUMAN Tregs GENE MODIFIED TO EXPRESS AN MBP-SPECIFIC TCR}

Another important disease studied in our lab is MS. We employ an EAE mouse model for MS. MS is a debilitating autoimmune disorder where effector T cells mediate the attack and destroy the myelin sheath of the central nervous system (CNS). This destruction results in relapsing/remitting symptoms or progressive paralysis, which could result in death in its most severe cases. The etiology of MS is unknown, but certain genetic and environmental factors may play a role (72-75). Current treatment options include immunosuppressive drugs, $\beta$-interferon, or Copaxone, a random amino acid copolymer (76-78). Recently, treatment with B-cell depleting antibodies such as ocrelizumab and rituximab (79-83), has been used to relieve symptoms, but their side effects can be severe and also can lead to global immunosuppression $(84,85)$. Better treatment options thus are clearly warranted. We believe that antigen-specific Tregs targeting CNS antigens implicated in MS can be such an option.

We engineered a construct to express a TCR sequence provided by Dr. Kai Wucherpfennig, who isolated the TCR from an autoreactive $\mathrm{CD}^{+} \mathrm{T}$ cell clone of an $\mathrm{MS}$ patient. This TCR, referred to as Ob2F3 (86-88), was specific for MBP epitope 85-99 and was HLA DR15 ("DR2") restricted. PBMC obtained from normal healthy donors were FACS-purified for nTregs, as we had done in the FVIII project, and transduced with the Ob2F3 TCR. These expanded, now MBP-specific, Tregs not only suppressed MBPspecific T-cell proliferation and cytokine production but also they could suppress FVIII-specific responses in vitro when both MBP and FVIII peptides were present. Remarkably, Ob2F3 TCR Tregs were also able to reduce myelin oligodendrocyte glycoprotein (MOG 35-55)-induced EAE symptoms in HLA DR2-transgenic mice. This was important because it confirmed that Tregs of one specificity (MBP) could exert bystander suppression of T effectors of another specificity (MOG), presumably in the local milieu. We found that these Ob2F3 TCR Tregs migrated in greater numbers to the CNS than non-specific Tregs and reduced the perivascular infiltrates in the spinal cord. This xenogeneic suppression validates the potency of antigen-specific engineered Tregs.

\section{MECHANISMS OF SUPPRESSION}

Understanding the suppression mechanism behind our genemodified human Tregs is also actively being pursued. Although 
it has been shown that Tregs have a diverse repertoire of suppression strategies both contact independent (contactless) and contact dependent (89-95), how these specifically modified Tregs suppress target cells is currently unresolved. While we know that bystander suppression could occur in vitro and in vivo, it was not clear whether cell-to-cell contact was needed. To investigate contactless and contact-driven mechanisms, our lab used a modified transwell developed by Dr. Kim that consisted of "heat-drilling" holes between microtiter wells so that liquid (and presumably effector suppressive molecules) could mix in the interwell space, dubbed the de-cellularized zone. We found that suppression of effector T-cell proliferation only occurred when specific Tregs and specific effector $\mathrm{T}$ cells were present together in the adjacent well (96).

We know that both effector and regulatory T cells need IL-2 to grow $(97,98)$. When we examined Stat5 phosphorylation kinetically, we found that antigen-stimulated effector $\mathrm{CD}^{+}$ $\mathrm{T}$ cells produced and responded to IL- 2 with Stat5 phosphorylation starting at $8 \mathrm{~h}$, but that Tregs alone showed minimal Stat5 phosphorylation even at $72 \mathrm{~h}$. However, when cocultured together, Treg Stat 5 phosphorylation started as early as $8 \mathrm{~h}$, at which time the $\mathrm{CD} 4^{+} \mathrm{T}$ cell effector response to IL-2 decreased dramatically. These results suggest that Tregs "co-opt" IL-2 from effector T cells and that a contact-dependent process was initiated with the production of more (long-acting) suppressive moieties.

To understand potential BAR Treg suppression mechanisms in our hemophilia A model, we designed a series of B and T cell coculture assays. Briefly, splenic B and T cells were isolated from A2 and C2 BAR Treg treated or non-specific control BAR Tregtreated FVIII-immunized hemophilic mice. T cells, isolated from A2 and C2 BAR Treg treated mice, were able to cooperate and stimulate antibody formation with $\mathrm{B}$ cells from control mice.
However, B cells isolated from A2- and C2-tolerized mice failed to be stimulated for anti-FVIII antibody production by control T cells. These observations strongly suggest that A2 and C2 BAR Tregs tolerized the B cell compartment while sparing that of T cells. Further experiments assessing whether A2 and C2 BAR domains are taken up by specific B cells (as exosomes or by trogocytosis?) or whether this tolerization of different compartment has a kinetic component (i.e., $\mathrm{T}$ cells become tolerized at a later time point) are underway.

To facilitate further mechanistic studies, we are reversing our trajectory back into murine systems. Our human Tregs are eventually rejected by the mouse immune system so trafficking studies, adoptive transfers and re-challenge experiments are not feasible. In addition, the use of knockout murine cells will aid in completing the mechanistic picture of gene-modified Tregs. These studies are in progress.

Please see Table 1 for summary of results.

\section{FUTURE DIRECTIONS AND CONSIDERATIONS FOR GENE-MODIFIED HUMAN Tregs}

T-cell receptor, CAR, and BAR Treg therapy all provide distinct advantages and (minor) disadvantages as therapeutics. All of these Tregs, while highly specific, can exhibit bystander suppression in the local milieu as demonstrated by their ability to suppress inhibitor formation to the entire FVIII protein in vitro and in vivo, despite being specific for a single domain or peptide epitopes. TCR gene-modified Tregs allow for targeting specific peptides presented by APC to pathogenic effector cells. The TCR also allows for the physiological activation and regulation of the

TABLE 1 | Types of antigen-specific human Tregs used in the Scott lab.

\begin{tabular}{|c|c|c|c|}
\hline Gene-modified hTreg & Specificity/target antigen & Disease model & Results \\
\hline $\begin{array}{l}17195 \text { T-cell receptor } \\
\text { (TCR) Tregs }\end{array}$ & $\begin{array}{l}\text { Human leukocyte antigen (HLA) } \\
\text { DR1-restricted FVIII epitope } \\
\text { (C2191-2210) }\end{array}$ & Hemophilia A & $\begin{array}{l}\text { - Expanded in an antigen-specific manner and maintained Treg } \\
\text { phenotype following long-term in vitro expansion } \\
\text { - Suppression of specific T effectors in vitro } \\
\text { - Suppressed FVIII-specific antibody production in vitro and in vivo } \\
\text { across a xenogeneic barrier } \\
\text { - Bystander suppression in the local milieu }\end{array}$ \\
\hline $\begin{array}{l}\text { ANS8 chimeric antigen } \\
\text { receptor (CAR) Tregs }\end{array}$ & A2 domain of FVIII & Hemophilia A & $\begin{array}{l}\text { - Expanded in an antigen-specific manner and maintained Treg } \\
\text { phenotype following long-term in vitro expansion } \\
\text { - Suppression of specific T effectors in vitro } \\
\text { - Suppressed FVIII-specific antibody production in vitro and in vivo } \\
\text { across a xenogeneic barrier } \\
\text { - Bystander suppression in the local milieu }\end{array}$ \\
\hline $\begin{array}{l}\text { A2 and C2 B-cell antibody } \\
\text { receptor (BAR) Tregs }\end{array}$ & $\begin{array}{l}\text { B-cell receptors specific for A2 } \\
\text { or } \mathrm{C} 2 \text { domains of FVIII }\end{array}$ & Hemophilia A & $\begin{array}{l}\text { - Expanded in an antigen-specific manner and maintained Treg } \\
\text { phenotype following long-term in vitro expansion } \\
\text { - Suppressed FVIII-specific antibody production in vitro and in vivo } \\
\text { across a xenogeneic barrier } \\
\text { - Bystander suppression in the local milieu } \\
\text { - Direct suppression of FVIII-specific B cells }\end{array}$ \\
\hline OB2F3 TCR Tregs & $\begin{array}{l}\text { HLA DR15-restricted myelin basic } \\
\text { protein epitope (MBP 85-99) }\end{array}$ & $\begin{array}{l}\text { Multiple sclerosis } \\
\text { [experimental autoimmune } \\
\text { encephalomyelitis (EAE)] }\end{array}$ & $\begin{array}{l}\text { - Suppressed MOG specific T cells in vitro } \\
\text { - Suppressed MOG peptide induced EAE across a xenogeneic barrier } \\
\text { - Trafficked to brain and spinal cord }\end{array}$ \\
\hline
\end{tabular}

The disease models in which they are tested and related results are listed and summarized, respectively. 
Tregs. However, the HLA restriction of TCR limits its utility to recipients sharing those HLA class II antigens. This is not as serious with MS, for example, as there is linkage to HLA DR2 (99). However, strong linkage to HLA has not been observed in hemophilia A (100). Nonetheless, there are five to seven most common DR phenotypes in North American Caucasians; conceivably, one could clone the $\mathrm{V}$ genes from the $\mathrm{T}$ cells of patients with these HLA DRs to create a repertoire of TCRs. Thus, screening for HLA or engineering TCRs de novo for each recipient is feasible today.

Chimeric antigen receptor gene-modified Tregs have the advantage of being HLA unrestricted. This greatly increases the universality of their usage as a therapeutic in all patients. These Tregs, like the TCR-transduced Tregs, can exhibit bystander suppression but need to recognize conformational domains in the target antigen. This is likely to occur in the context of cell surfaces, either dendritic or endothelial cells or specific B cells, before uptake. The scFv we have used was obtained by phage display (65). Thus, further scFvs against other domains of FVIII can readily be produced.

B-cell antibody receptor Tregs represent a novel approach for engineering gene-modified antigen-specific cells; these too are not HLA-restricted and only require that specific B cells can bind via their surface Ig receptors to the domains expressed on the Tregs. Originally, our lab envisioned this approach for targeting inhibitors in hemophilia A or responses to biotherapeutics in monogenic diseases, but they also can be designed to target pathogenic antibodies in autoimmunity or antidrug antibodies $(101,102)$. An issue with BARs Tregs (or BAR CD8 killer T cells) is that circulating antibodies may bind to the BAR Treg epitope domains and either neutralize their activity or cause tonic signaling to drive an exhausted phenotype. While a concern, we think this is unlikely since we have found that antibody crosslinking of the BAR can, in some instances, trigger Treg proliferation. In addition, plasmapheresis could be used to remove the circulating antibodies if needed, but these may not possess as high an affinity for the BAR as the isotype-switched memory B cells.

Much remains to be discovered regarding specific Treg suppression mechanisms. We already know that, aside from bystander suppression which occurs locally, the contiguous presence of effector T cells and Tregs can lead to enhanced suppressive activity and contactless suppression of other T cells. This is in part due to the fact that effector cells require much higher amounts of IL-2 to maintain proliferation compared to Tregs, which acquire IL-2 locally and rapidly phosphorylate Stat5 downstream of CD25. How this process activate the Tregs to produce suppressive moieties is unknown but under investigation.

How Tregs modulate antibody formation is not clear. Obviously, suppression of effector (helper) $\mathrm{T}$ cell activation is involved. In a preliminary experiment, culture of $\mathrm{T}$ and $\mathrm{B}$ cells from BAR Treg-tolerized hosts suggests that B cells may be directly targeted (at least by BAR Tregs). We have no evidence at present for direct toxicity of BAR Tregs on B cells, but this remains an open question since human CD4 ${ }^{+} \mathrm{T}$ cells can be cytotoxic $(103,104)$.

A major concern of any gene-modified cellular therapy is safety. Fortunately, technologies such as inducible suicide genes can be applied to gene-modified Tregs (105). For example, this technology would be a protection in the unlikely event in which bystander suppression led to any unintended sequelae.

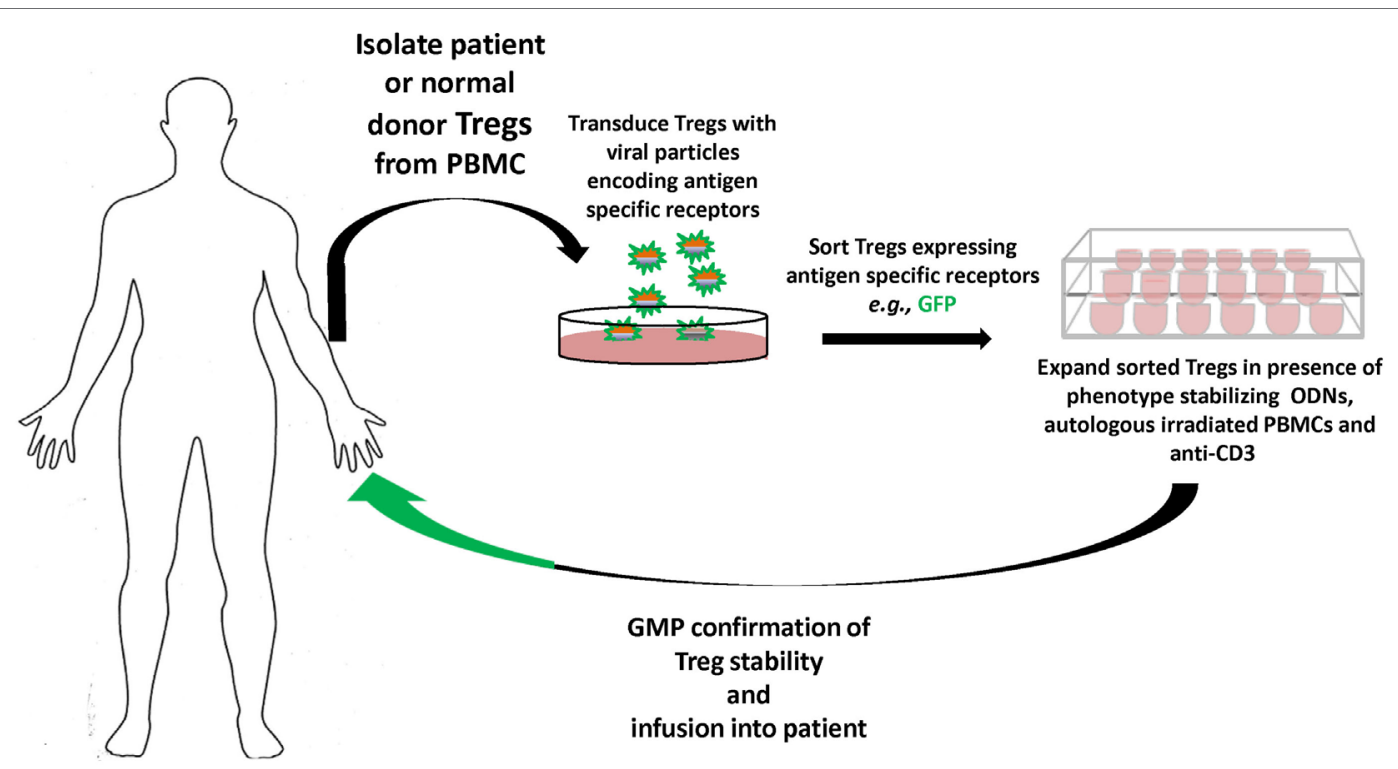

FIGURE 2 | Overview of gene-modified antigen-specific human Treg therapy. Patient (or normal donor) blood is collected, and Tregs are sorted from buffy coat, and virally transduced to express specific receptors [T-cell receptor (TCR), chimeric antigen receptor, or B-cell antibody receptor]. The antigen-specific Tregs are then sorted and expanded in the presence of autologous peripheral blood mononuclear cells (PBMCs), anti-CD3, and oligodeoxynucleotides (ODN), which stabilize Treg functional characteristics during expansion. The antigen-specific Tregs that meet robust GMP standards and Treg phenotype are then infused back into the patient tracking of the Tregs in vivo can be performed by deuterium labeling or GFP expression. Safety constructs that trigger the ablation or death of the infused antigen-specific Tregs can also be integrated, and gene editing by CRISPR/Cas9, e.g., used to remove endogenous TCRs or MHC to avoid graft versus host disease or rejection, respectively, of generic donor $\mathrm{T}$ cells. 
In addition, we would like to create specific Tregs from generic, "off-the-shelf" unrelated donors. While such cells would possess endogenous TCRs and foreign HLA, we plan to apply techniques, such as CRISPR/Cas9 or TALENs $(106,107)$, to engineer out the endogenous TCRs so that these Tregs would only possess the transduced TCR, CAR, or BAR and would not cause GVHD disease. In addition, deleting HLA class II would also prevent their rejection by an immunocompetent host. Expansion of Tregs and their stable phenotype are also important concerns in advancing gene-modified Treg therapy. It is estimated that a minimal dosage of $1-3 \times 10^{6} / \mathrm{kg}$ of Treg may be needed for therapy efficacy (108). As mentioned, the ODN protocol has proven effective in maintaining the human Treg phenotype and function throughout the necessary expansion phase.

Designing treatments for an ongoing and established autoimmune diseases can pose a significant hurdle. Typically, autoimmune patients first visit their physicians after disease symptoms have appeared. The dysregulation and disruption of self-tolerance leading to diabetes, lupus, or MS, for example, typically can occur over an extended asymptomatic or subclinical time period. However, predictive measures in addition to family history are being developed. Therefore, antigen-specific Treg therapy could be administered to these patients to prevent pathological damage. Our data suggest we may even be able to attenuate symptoms once they arise. While there can be multiple (and unknown) target antigens in autoimmune diseases, we have shown in our EAE/ MS model that gene-modified antigen-specific Treg therapy can exhibit bystander tolerance for other antigens in the local milieu.

\section{REFERENCES}

1. Hori S, Nomura T, Sakaguchi S. Control of regulatory T cell development by the transcription factor Foxp3. Science (2003) 299(5609):1057-61. doi:10.1126/science. 1079490

2. Sakaguchi S, Sakaguchi N, Asano M, Itoh M, Toda M. Immunologic selftolerance maintained by activated $\mathrm{T}$ cells expressing IL-2 receptor alphachains (CD25). Breakdown of a single mechanism of self-tolerance causes various autoimmune diseases. J Immunol (1995) 155(3):1151-64.

3. Sakaguchi S. The origin of FOXP3-expressing CD4+ regulatory T cells: thymus or periphery. J Clin Invest (2003) 112(9):1310-2. doi:10.1172/ JCI200320274

4. Fontenot JD, Gavin MA, Rudensky AY. Foxp3 programs the development and function of CD4+CD25+ regulatory T cells. Nat Immunol (2003) 4(4):330-6. doi:10.1038/ni904

5. Bacchetta R, Passerini L, Gambineri E, Dai M, Allan SE, Perroni L, et al. Defective regulatory and effector $\mathrm{T}$ cell functions in patients with FOXP3 mutations. J Clin Invest (2006) 116(6):1713-22. doi:10.1172/JCI25112

6. Sakaguchi S, Yamaguchi T, Nomura T, Ono M. Regulatory T cells and immune tolerance. Cell (2008) 133(5):775-87. doi:10.1016/j.cell.2008.05.009

7. Tang TT, Zhu ZF, Wang J, Zhang WC, Tu X, Xiao H, et al. Impaired thymic export and apoptosis contribute to regulatory T-cell defects in patients with chronic heart failure. PLoS One (2011) 6(9):e24272. doi:10.1371/journal. pone. 0024272

8. Kim JM, Rasmussen JP, Rudensky AY. Regulatory T cells prevent catastrophic autoimmunity throughout the lifespan of mice. Nat Immunol (2007) 8(2):191-7. doi:10.1038/ni1428

9. Komatsu N, Okamoto K, Sawa S, Nakashima T, Oh-hora M, Kodama T, et al. Pathogenic conversion of Foxp3+ T cells into TH17 cells in autoimmune arthritis. Nat Med (2014) 20(1):62-8. doi:10.1038/nm.3432

10. Gross G, Waks T, Eshhar Z. Expression of immunoglobulin-T-cell receptor chimeric molecules as functional receptors with antibody-type specificity. Proc Natl Acad Sci U S A (1989) 86(24):10024-8. doi:10.1073/pnas.86.24.10024
In terms of responses to biotherapeutics, as in hemophilia A or monogenic diseases like Pompe's, the specific antigens are known, as is family history; hence, gene-modified antigen-specific human Tregs can become viable therapies prophylactically, as well as therapeutically. Our results suggest that antigen-specific TCR, CAR, and BAR Tregs each have distinct advantages as therapeutics and, thus, cultivation of each is necessary. Current progress toward good manufacturing practice and economy of scales are now being optimized. The future promise of gene-modified specific human Tregs therapeutics is quickly becoming today's reality (Figure 2).

\section{AUTHOR CONTRIBUTIONS}

PA and DS: writing organization of manuscript citations and creation of figures. YK, A-HZ, and JY: proofreading and discussion.

\section{ACKNOWLEDGMENTS}

The studies summarized in this review have been supported by grants from the National Institutes of Health (RO1 HL126727 and R21 HL127495), the National Multiple Sclerosis Society, and an ASPIRE award from Pfizer. The authors are grateful to Drs. Anja N. Schmidt and Christoph Königs for the scFv, Drs. Kathleen Pratt and Kai Wucherpfennig for TCR sequences, and to Dr. Maha Abdeladhim and Kalpana Parvathaneni for valuable discussion and a critical reading of the manuscript.

11. Clay TM, Custer MC, Sachs J, Hwu P, Rosenberg SA, Nishimura MI. Efficient transfer of a tumor antigen-reactive TCR to human peripheral blood lymphocytes confers anti-tumor reactivity. J Immunol (1999) 163(1): 507-13.

12. Hull CM, Nickolay LE, Estorninho M, Richardson MW, Riley JL, Peakman M, et al. Generation of human islet-specific regulatory T cells by TCR gene transfer. J Autoimmun (2017) 79:63-73. doi:10.1016/j.jaut.2017.01.001

13. Rosenberg SA, Aebersold P, Cornetta K, Kasid A, Morgan RA, Moen R, et al. Gene transfer into humans - immunotherapy of patients with advanced melanoma, using tumor-infiltrating lymphocytes modified by retroviral gene transduction. N Engl J Med (1990) 323(9):570-8. doi:10.1056/ NEJM199008303230904

14. Restorick SM, Durant L, Kalra S, Hassan-Smith G, Rathbone E, Douglas MR, et al. CCR6+ Th cells in the cerebrospinal fluid of persons with multiple sclerosis are dominated by pathogenic non-classic Th1 cells and GM-CSFonly-secreting Th cells. Brain Behav Immun (2017) 64:71-9. doi:10.1016/j. bbi.2017.03.008

15. Chitnis T. The role of CD4 T cells in the pathogenesis of multiple sclerosis. Int Rev Neurobiol (2007) 79:43-72. doi:10.1016/S0074-7742(07)79003-7

16. Pini A, Viti F, Santucci A, Carnemolla B, Zardi L, Neri P, et al. Design and use of a phage display library. Human antibodies with subnanomolar affinity against a marker of angiogenesis eluted from a two-dimensional gel. J Biol Chem (1998) 273(34):21769-76. doi:10.1074/jbc.273.34.21769

17. Tomita M, Tsumoto K. Hybridoma technologies for antibody production. Immunotherapy (2011) 3(3):371-80. doi:10.2217/imt.11.4

18. Kohler G, Milstein C. Continuous cultures of fused cells secreting antibody of predefined specificity. Nature (1975) 256(5517):495-7. doi:10.1038/256495a0

19. Winter G, Griffiths AD, Hawkins RE, Hoogenboom HR. Making antibodies by phage display technology. Annu Rev Immunol (1994) 12:433-55. doi:10.1146/ annurev.iy.12.040194.002245

20. Parvathaneni K, Abdeladhim M, Pratt KP, Scott DW. Hemophilia A inhibitor treatment: the promise of engineered T-cell therapy. Transl Res (2017) 187:44-52. doi:10.1016/j.trsl.2017.06.002 
21. Barrett DM, Grupp SA, June CH. Chimeric antigen receptor- and TCRmodified $\mathrm{T}$ cells enter main street and wall street. JImmunol (2015) 195(3):755-61. doi:10.4049/jimmunol.1500751

22. Chang ZL, Chen YY. CARs: synthetic immunoreceptors for cancer therapy and beyond. Trends Mol Med (2017) 23:430-50. doi:10.1016/j.molmed.2017. 03.002

23. Jackson HJ, Rafiq S, Brentjens RJ. Driving CAR T-cells forward. Nat Rev Clin Oncol (2016) 13(6):370-83. doi:10.1038/nrclinonc.2016.36

24. June CH. Adoptive T cell therapy for cancer in the clinic. J Clin Invest (2007) 117(6):1466-76. doi:10.1172/JCI32446

25. Vonderheide $\mathrm{RH}$, June $\mathrm{CH}$. Engineering $\mathrm{T}$ cells for cancer: our synthetic future. Immunol Rev (2014) 257(1):7-13. doi:10.1111/imr.12143

26. Ellebrecht CT, Bhoj VG, Nace A, Choi EJ, Mao X, Cho MJ, et al. Reengineering chimeric antigen receptor $\mathrm{T}$ cells for targeted therapy of autoimmune disease. Science (2016) 353(6295):179-84. doi:10.1126/science.aaf6756

27. Chen ML, Yan BS, Bando Y, Kuchroo VK, Weiner HL. Latency-associated peptide identifies a novel $\mathrm{CD} 4+\mathrm{CD} 25+$ regulatory $\mathrm{T}$ cell subset with TGFbeta-mediated function and enhanced suppression of experimental autoimmune encephalomyelitis. J Immunol (2008) 180(11):7327-37. doi:10.4049/ jimmunol.180.11.7327

28. Ephrem A, Epstein AL, Stephens GL, Thornton AM, Glass D, Shevach EM. Modulation of Treg cells/T effector function by GITR signaling is contextdependent. Eur J Immunol (2013) 43(9):2421-9. doi:10.1002/eji.201343451

29. Floess S, Freyer J, Siewert C, Baron U, Olek S, Polansky J, et al. Epigenetic control of the foxp3 locus in regulatory T cells. PLoS Biol (2007) 5(2):e38. doi:10.1371/journal.pbio.0050038

30. Koenen HJ, Fasse E, Joosten I. CD27/CFSE-based ex vivo selection of highly suppressive alloantigen-specific human regulatory T cells. J Immunol (2005) 174(12):7573-83. doi:10.4049/jimmunol.174.12.7573

31. Mack DG, Lanham AM, Palmer BE, Maier LA, Fontenot AP. CD27 expression on $\mathrm{CD} 4+\mathrm{T}$ cells differentiates effector from regulatory $\mathrm{T}$ cell subsets in the lung. J Immunol (2009) 182(11):7317-24. doi:10.4049/jimmunol. 0804305

32. Sun L, Jin H, Li H. GARP: a surface molecule of regulatory T cells that is involved in the regulatory function and TGF-beta releasing. Oncotarget (2016) 7(27):42826-36. doi:10.18632/oncotarget.8753

33. Takahashi T, Tagami T, Yamazaki S, Uede T, Shimizu J, Sakaguchi N, et al. Immunologic self-tolerance maintained by $\mathrm{CD} 25(+) \mathrm{CD} 4(+)$ regulatory $\mathrm{T}$ cells constitutively expressing cytotoxic T lymphocyte-associated antigen 4 . J Exp Med (2000) 192(2):303-10. doi:10.1084/jem.192.2.303

34. Wang R, Kozhaya L, Mercer F, Khaitan A, Fujii H, Unutmaz D. Expression of GARP selectively identifies activated human FOXP3+ regulatory T cells. Proc Natl Acad Sci U S A (2009) 106(32):13439-44. doi:10.1073/pnas. 0901965106

35. Alam MS, Kurtz CC, Rowlett RM, Reuter BK, Wiznerowicz E, Das S, et al. CD73 is expressed by human regulatory T helper cells and suppresses proinflammatory cytokine production and Helicobacter felis-induced gastritis in mice. J Infect Dis (2009) 199(4):494-504. doi:10.1086/596205

36. Baecher-Allan C, Wolf E, Hafler DA. MHC class II expression identifies functionally distinct human regulatory T cells. J Immunol (2006) 176(8):4622-31. doi:10.4049/jimmunol.176.8.4622

37. Brunkow ME, Jeffery EW, Hjerrild KA, Paeper B, Clark LB, Yasayko SA, et al. Disruption of a new forkhead/winged-helix protein, scurfin, results in the fatal lymphoproliferative disorder of the scurfy mouse. Nat Genet (2001) 27(1):68-73. doi:10.1038/83784

38. Ramsdell F, Ziegler SF. FOXP3 and scurfy: how it all began. Nat Rev Immunol (2014) 14(5):343-9. doi:10.1038/nri3650

39. Bennett CL, Christie J, Ramsdell F, Brunkow ME, Ferguson PJ, Whitesell L, et al. The immune dysregulation, polyendocrinopathy, enteropathy, X-linked syndrome (IPEX) is caused by mutations of FOXP3. Nat Genet (2001) 27(1):20-1. doi:10.1038/83713

40. Le Bras S, Geha RS. IPEX and the role of Foxp3 in the development and function of human Tregs. JClin Invest (2006) 116(6):1473-5. doi:10.1172/ JCI28880

41. Kohm AP, McMahon JS, Podojil JR, Begolka WS, DeGutes M, Kasprowicz DJ, et al. Cutting edge: anti-CD25 monoclonal antibody injection results in the functional inactivation, not depletion, of CD4+CD25+ T regulatory cells. J Immunol (2006) 176(6):3301-5. doi:10.4049/jimmunol. 176.6.3301
42. Mottet C, Uhlig HH, Powrie F. Cutting edge: cure of colitis by CD4+CD25+ regulatory T cells. J Immunol (2003) 170(8):3939-43. doi:10.4049/jimmunol. 170.8 .3939

43. Majowicz A, van der Marel S, te Velde AA, Meijer SL, Petry H, van Deventer SJ, et al. Murine CD4(+)CD25(-) cells activated in vitro with $\mathrm{PMA} /$ ionomycin and anti-CD3 acquire regulatory function and ameliorate experimental colitis in vivo. BMC Gastroenterol (2012) 12:172. doi:10.1186/ 1471-230X-12-172

44. Ogino $\mathrm{H}$, Nakamura $\mathrm{K}$, Iwasa $\mathrm{T}$, Ihara $\mathrm{E}$, Akiho $\mathrm{H}$, Motomura $\mathrm{Y}$, et al. Regulatory $\mathrm{T}$ cells expanded by rapamycin in vitro suppress colitis in an experimental mouse model. J Gastroenterol (2012) 47(4):366-76. doi:10.1007/ s00535-011-0502-y

45. Silver PB, Horai R, Chen J, Jittayasothorn Y, Chan CC, Villasmil R, et al. Retina-specific $\mathrm{T}$ regulatory cells bring about resolution and maintain remission of autoimmune uveitis. J Immunol (2015) 194(7):3011-9. doi:10.4049/ jimmunol.1402650

46. Wright GP, Notley CA, Xue SA, Bendle GM, Holler A, Schumacher TN, et al. Adoptive therapy with redirected primary regulatory $\mathrm{T}$ cells results in antigen-specific suppression of arthritis. Proc Natl Acad Sci U S A (2009) 106(45):19078-83. doi:10.1073/pnas.0907396106

47. Brunstein CG, Blazar BR, Miller JS, Cao Q, Hippen KL, McKenna DH, et al. Adoptive transfer of umbilical cord blood-derived regulatory $\mathrm{T}$ cells and early viral reactivation. Biol Blood Marrow Transplant (2013) 19(8):1271-3. doi:10.1016/j.bbmt.2013.06.004

48. Bluestone JA, Buckner JH, Fitch M, Gitelman SE, Gupta S, Hellerstein MK, et al. Type 1 diabetes immunotherapy using polyclonal regulatory $\mathrm{T}$ cells. Sci Transl Med (2015) 7(315):315ra189. doi:10.1126/scitranslmed.aad4134

49. Gitelman SG, Griffin K, Herold K, Moran A. Phase 2 Product Candidate for Recent-Onset Type I Diabetes. (2017). Available from: http://www.caladrius. com/product-candidates/clbs03/

50. Nishikawa H, Sakaguchi S. Regulatory T cells in cancer immunotherapy. Curr Opin Immunol (2014) 27:1-7. doi:10.1016/j.coi.2013.12.005

51. Tanaka A, Sakaguchi S. Regulatory T cells in cancer immunotherapy. Cell Res 2017 27(1):109-18. doi:10.1038/cr.2016.151

52. Sakaguchi S, Miyara M, Costantino CM, Hafler DA. FOXP3+ regulatory $\mathrm{T}$ cells in the human immune system. Nat Rev Immunol (2010) 10(7):490-500. doi:10.1038/nri2785

53. Yuan X, Cheng G, Malek TR. The importance of regulatory T-cell heterogeneity in maintaining self-tolerance. Immunol Rev (2014) 259(1):103-14. doi:10.1111/imr.12163

54. Cheng Y, Wong MT, van der Maaten L, Newell EW. Categorical analysis of human $\mathrm{T}$ cell heterogeneity with one-dimensional soli-expression by nonlinear stochastic embedding. J Immunol (2016) 196(2):924-32. doi:10.4049/ jimmunol.1501928

55. Jenkins $\mathrm{MK}$, Moon JJ. The role of naive $\mathrm{T}$ cell precursor frequency and recruitment in dictating immune response magnitude. JImmunol (2012) 188(9):4135-40. doi:10.4049/jimmunol.1102661

56. Deviren G, Gupta K, Paulaitis ME, Schneck JP. Detection of antigen-specific T cells on p/MHC microarrays. J Mol Recognit (2007) 20(1):32-8. doi:10.1002/ jmr.805

57. Ettinger RA, James EA, Kwok WW, Thompson AR, Pratt KP. HLA-DRrestricted T-cell responses to factor VIII epitopes in a mild haemophilia A family with missense substitution A2201P. Haemophilia (2010) 16(102):44-55. doi:10.1111/j.1365-2516.2008.01905.x

58. James EA, Bui J, Berger D, Huston L, Roti M, Kwok WW. Tetramer-guided epitope mapping reveals broad, individualized repertoires of tetanus toxinspecific CD4+ T cells and suggests HLA-based differences in epitope recognition. Int Immunol (2007) 19(11):1291-301. doi:10.1093/intimm/dxm099

59. Kwong GA, Radu CG, Hwang K, Shu CJ, Ma C, Koya RC, et al. Modular nucleic acid assembled $\mathrm{p} / \mathrm{MHC}$ microarrays for multiplexed sorting of antigenspecific T cells. JAm Chem Soc (2009) 131(28):9695-703. doi:10.1021/ ja9006707

60. Cromwell C, Aledort LM. FEIBA: a prohemostatic agent. Semin Thromb Hemost (2012) 38(3):265-7. doi:10.1055/s-0032-1309286

61. Ragni MV, Bontempo FA, Lewis JH. Disappearance of inhibitor to factor VIII in HIV-infected hemophiliacs with progression to AIDS or severe ARC. Transfusion (1989) 29(5):447-9. doi:10.1046/j.1537-2995.1989.29589284147.x

62. Ettinger RA, James EA, Kwok WW, Thompson AR, Pratt KP. Lineages of human T-cell clones, including T helper 17/T helper 1 cells, isolated at different 
stages of anti-factor VIII immune responses. Blood (2009) 114(7):1423-8. doi:10.1182/blood-2009-01-200725

63. Kim YC, Zhang AH, Su Y, Rieder SA, Rossi RJ, Ettinger RA, et al. Engineered antigen-specific human regulatory $\mathrm{T}$ cells: immunosuppression of FVIIIspecific T- and B-cell responses. Blood (2015) 125(7):1107-15. doi:10.1182/ blood-2014-04-566786

64. Kim YC, Bhairavabhotla R, Yoon J, Golding A, Thornton AM, Tran DQ, et al. Oligodeoxynucleotides stabilize Helios-expressing Foxp3+ human $\mathrm{T}$ regulatory cells during in vitro expansion. Blood (2012) 119(12):2810-8. doi:10.1182/blood-2011-09-377895

65. Yoon J, Schmidt A, Zhang AH, Konigs C, Kim YC, Scott DW. FVIIIspecific human chimeric antigen receptor T-regulatory cells suppress T- and B-cell responses to FVIII. Blood (2017) 129(2):238-45. doi:10.1182/ blood-2016-07-727834

66. Naumann A, Scherger AK, Neuwirth J, Orlowski A, Kahle J, Schwabe D, et al. Selection and characterisation of FVIII-specific single chain variable fragments. Hamostaseologie (2013) 33(Suppl 1):S39-45.

67. Kinnunen T, Chamberlain N, Morbach H, Choi J, Kim S, Craft J, et al. Accumulation of peripheral autoreactive B cells in the absence of functional human regulatory T cells. Blood (2013) 121(9):1595-603. doi:10.1182/ blood-2012-09-457465

68. Tsuda M, Torgerson TR, Selmi C, Gambineri E, Carneiro-Sampaio M, Mannurita SC, et al. The spectrum of autoantibodies in IPEX syndrome is broad and includes anti-mitochondrial autoantibodies. J Autoimmun (2010) 35(3):265-8. doi:10.1016/j.jaut.2010.06.017

69. Wardemann H, Yurasov S, Schaefer A, Young JW, Meffre E, Nussenzweig MC. Predominant autoantibody production by early human B cell precursors. Science (2003) 301(5638):1374-7. doi:10.1126/science.1086907

70. Weingartner E, Courneya JP, Keegan A, Golding A. A novel method for assaying human regulatory $\mathrm{T}$ cell direct suppression of $\mathrm{B}$ cell effector function. J Immunol Methods (2017) 441:1-7. doi:10.1016/j.jim.2016.11.004

71. Zhang A-H, Yoon J, Kim YC, Scott DW. Targeting FVIII-specific B cells using BAR-transduced regulatory T cells. Blood (2016) 128:329.

72. Handel AE, Giovannoni G, Ebers GC, Ramagopalan SV. Environmental factors and their timing in adult-onset multiple sclerosis. Nat Rev Neurol (2010) 6(3):156-66. doi:10.1038/nrneurol.2010.1

73. Ramagopalan SV, Dobson R, Meier UC, Giovannoni G. Multiple sclerosis: risk factors, prodromes, and potential causal pathways. Lancet Neurol (2010) 9(7):727-39. doi:10.1016/S1474-4422(10)70094-6

74. Sadovnick AD, Ebers GC. Genetics of multiple sclerosis. Neurol Clin (1995) 13(1):99-118.

75. Rose AM, Bell LC. Epistasis and immunity: the role of genetic interactions in autoimmune diseases. Immunology (2012) 137(2):131-8. doi:10.1111/ j.1365-2567.2012.03623.x

76. Arnason BG. Treatment of multiple sclerosis with interferon beta. Biomed Pharmacother (1999) 53(8):344-50. doi:10.1016/S0753-3322(99) 80105-X

77. Johnson KP. Management of relapsing/remitting multiple sclerosis with copolymer 1 (Copaxone). Mult Scler (1996) 1(6):325-6. doi:10.1177/ 135245859600100606

78. Ross CJ, Towfic F, Shankar J, Laifenfeld D, Thoma M, Davis M, et al. A pharmacogenetic signature of high response to Copaxone in late-phase clinical-trial cohorts of multiple sclerosis. Genome Med (2017) 9(1):50. doi:10.1186/s13073-017-0436-y

79. de Flon P, Laurell K, Soderstrom L, Gunnarsson M, Svenningsson A. Improved treatment satisfaction after switching therapy to rituximab in relapsingremitting MS. Mult Scler (2017) 23:1249-57. doi:10.1177/1352458516676643

80. Lulu S, Waubant E. Humoral-targeted immunotherapies in multiple sclerosis. Neurotherapeutics (2013) 10(1):34-43. doi:10.1007/s13311-0120164-3

81. Montalban X, Hauser SL, Kappos L, Arnold DL, Bar-Or A, Comi G, et al. Ocrelizumab versus placebo in primary progressive multiple sclerosis. $N$ Engl J Med (2017) 376(3):209-20. doi:10.1056/NEJMoa1606468

82. Moreno Torres I, Garcia-Merino A. Anti-CD20 monoclonal antibodies in multiple sclerosis. Expert Rev Neurother 2017 17(4):359-71. doi:10.1080/ 14737175.2017.1245616

83. Petereit HF, Moeller-Hartmann W, Reske D, Rubbert A. Rituximab in a patient with multiple sclerosis - effect on B cells, plasma cells and intrathecal IgG synthesis. Acta Neurol Scand (2008) 117(6):399-403. doi:10.1111/j.1600-0404.2007.00958.x

84. McGinley MP, Moss BP, Cohen JA. Safety of monoclonal antibodies for the treatment of multiple sclerosis. Expert Opin Drug Saf (2017) 16(1):89-100. doi:10.1080/14740338.2017.1250881

85. Salzer J, Svenningsson R, Alping P, Novakova L, Bjorck A, Fink K, et al. Rituximab in multiple sclerosis: a retrospective observational study on safety and efficacy. Neurology (2016) 87(20):2074-81. doi:10.1212/ WNL.0000000000003331

86. Kato Z, Stern JN, Nakamura HK, Kuwata K, Kondo N, Strominger JL. Positioning of autoimmune TCR-Ob.2F3 and TCR-Ob.3D1 on the MBP8599/HLA-DR2 complex. Proc Natl Acad Sci U S A (2008) 105(40):15523-8. doi:10.1073/pnas.0807338105

87. Wucherpfennig KW, Ota K, Endo N, Seidman JG, Rosenzweig A, Weiner HL, et al. Shared human $\mathrm{T}$ cell receptor $\mathrm{V}$ beta usage to immunodominant regions of myelin basic protein. Science (1990) 248(4958):1016-9. doi:10.1126/ science. 1693015

88. Wucherpfennig KW, Weiner HL, Hafler DA. T-cell recognition of myelin basic protein. Immunol Today (1991) 12(8):277-82. doi:10.1016/01675699(91)90126-E

89. Baatar D, Olkhanud P, Sumitomo K, Taub D, Gress R, Biragyn A. Human peripheral blood T regulatory cells (Tregs), functionally primed CCR4+ Tregs and unprimed CCR4- Tregs, regulate effector T cells using FasL. J Immunol (2007) 178(8):4891-900. doi:10.4049/jimmunol.178.8.4891

90. Schmidt A, Oberle N, Krammer PH. Molecular mechanisms of tregmediated T cell suppression. Front Immunol (2012) 3:51. doi:10.3389/ fimmu.2012.00051

91. Tran DQ, Glass DD, Uzel G, Darnell DA, Spalding C, Holland SM, et al. Analysis of adhesion molecules, target cells, and role of IL-2 in human FOXP3+ regulatory $\mathrm{T}$ cell suppressor function. JImmunol (2009) 182(5):2929-38. doi:10.4049/jimmunol.0803827

92. Vignali DA. Mechanisms of T(reg) suppression: still a long way to go. Front Immunol (2012) 3:191. doi:10.3389/fimmu.2012.00191

93. Zhang Q, Chikina M, Szymczak-Workman AL, Horne W, Kolls JK, Vignali KM, et al. LAG3 limits regulatory T cell proliferation and function in autoimmune diabetes. Sci Immunol 2017 2(9):eaah4569. doi:10.1126/ sciimmunol.aah4569

94. Hagness M, Henjum K, Landskron J, Brudvik KW, Bjornbeth BA, Foss A, et al. Kinetics and activation requirements of contact-dependent immune suppression by human regulatory T cells. J Immunol (2012) 188(11):5459-66. doi:10.4049/jimmunol.1101367

95. Shevach EM. Mechanisms of foxp3+ T regulatory cell-mediated suppression. Immunity (2009) 30(5):636-45. doi:10.1016/j.immuni.2009.04.010

96. Kim YC, Zhang A-H, Yoon JH, Wucherpfennig K, Scott D. Engineered myelin basic protein (MBP)-specific human $\mathrm{T}$ regulatory cells ameliorate myelin oligodendrocyte glycoprotein (MOG) peptide-induced Experimental Autoimmune Encephalomyelitis in vivo. J Immunol (2017) 198(1 Supplement):219.15.

97. Smith KA. Interleukin-2: inception, impact, and implications. Science (1988) 240(4856):1169-76. doi:10.1126/science.3131876

98. Boyman O, Sprent J. The role of interleukin-2 during homeostasis and activation of the immune system. Nat Rev Immunol (2012) 12(3):180-90. doi:10.1038/nri3156

99. Luckey D, Bastakoty D, Mangalam AK. Role of HLA class II genes in susceptibility and resistance to multiple sclerosis: studies using HLA transgenic mice. J Autoimmun (2011) 37(2):122-8. doi:10.1016/j.jaut.2011.05.001

100. Oldenburg J, Picard JK, Schwaab R, Brackmann HH, Tuddenham EG, Simpson E. HLA genotype of patients with severe haemophilia A due to intron 22 inversion with and without inhibitors of factor VIII. Thromb Haemost (1997) 77(2):238-42.

101. Ridker PM, Tardif JC, Amarenco P, Duggan W, Glynn RJ, Jukema JW, et al. Lipid-reduction variability and antidrug-antibody formation with bococizumab. N Engl J Med (2017) 376(16):1517-26. doi:10.1056/ NEJMoa1614062

102. Kolata G. When the Immune System Thwarts Lifesaving Drugs, New York Times. The New York Times. Dean Baquet (2017). Available from: https:// www.nytimes.com/2017/05/15/health/immune-system-drugs-monoclonal-antibodies.html?emc=eta1\&_r=0 
103. van de Berg PJ, van Leeuwen EM, ten Berge IJ, van Lier R. Cytotoxic human CD4(+) T cells. Curr Opin Immunol (2008) 20(3):339-43. doi:10.1016/j. coi.2008.03.007

104. Weiskopf D, Bangs DJ, Sidney J, Kolla RV, De Silva AD, de Silva AM, et al. Dengue virus infection elicits highly polarized CX3CR1+ cytotoxic CD4+ T cells associated with protective immunity. Proc Natl Acad Sci U S A (2015) 112(31):E4256-63. doi:10.1073/pnas.1505956112

105. Tey SK. Adoptive T-cell therapy: adverse events and safety switches. Clin Transl Immunology (2014) 3(6):e17. doi:10.1038/cti.2014.11

106. Nemudryi AA, Valetdinova KR, Medvedev SP, Zakian SM. TALEN and CRISPR/Cas genome editing systems: tools of discovery. Acta Naturae (2014) 6(3):19-40.

107. Kim JS. Genome editing comes of age. Nat Protoc (2016) 11(9):1573-8. doi:10.1038/nprot.2016.104
108. Parmar S, Shpall EJ. Treg adoptive therapy: is more better? Blood (2016) 127(8):962-3. doi:10.1182/blood-2015-12-682492

Conflict of Interest Statement: The authors declare that the research was conducted in the absence of any commercial or financial relationships that could be construed as a potential conflict of interest.

Copyright (c) 2017 Adair, Kim, Zhang, Yoon and Scott. This is an open-access article distributed under the terms of the Creative Commons Attribution License (CC BY). The use, distribution or reproduction in other forums is permitted, provided the original author(s) or licensor are credited and that the original publication in this journal is cited, in accordance with accepted academic practice. No use, distribution or reproduction is permitted which does not comply with these terms. 